\title{
Studies on the Utilization of the Riparian Zone of Three Gorges Reservoir in China: a Literature Review
}

\author{
Guan Yuan \\ No.2 High School of East China Normal University, China \\ 2608084175@qq.com
}

Keywords: Riparian zone, Evaluation, Three-gorges reservoir, Utilization, Hydro-fluctuation zone

\begin{abstract}
Riparian areas are ecosystems with significant value in various aspects, which have been recognized since 1970s, when the United States held an academic seminar on the conversation, management, and importance of riparian habitats. The properties of these areas would affect adjacent water quality and ecosystem. Besides, they could be utilized for several positive aims due to the unique characteristics. In this paper all scientific publications related to the utilization of riparian areas of Three Gorges Reservoir are reviewed and categorized. To accomplish this, online search engines were used. The key words were "riparian” and “Three Gorges Reservoir.” Twenty seven publications were found with most published in scientific journal (70\%) and primarily after the year of 2006 (95\%). These publications covered a wide range of thematic categories such as the ecology of riparian areas, the abiotic parameters that influence these ecosystems, the anthropogenic impacts on them, their proper management and the potential measures to utilize them. The results showed that the awareness regarding the riparian areas of Three Gorges has increased in the last two decades especially after the construction of Three Gorges Dams. However, comparing searching results from "CNKI" with "web of science”, "Europe PMC" and "Science Direct”, Chinese scholars have nearly no systematic studies on the economic evaluation of riparian zones. Most of the relevant scientific publications focus on one aspect of the Three Gorges Reservoir riparian zone, such as the agro-ecological utilization, the environmental conditions, and the tourism utilization. These aspects do cover many approaches to measure the value and discuss the management of the riparian zone. Nevertheless, some general assessment is still in need.
\end{abstract}

\section{Introduction}

Riparian zone, also known as water-level fluctuation zone, buffer zone, etc., refer to flooded land that periodically emerge from the water surface because of the seasonal fluctuation of water level in rivers, lakes, or reservoirs. It is a special part of land, serves an important role in ecology and environmental resource management, and could bring economic benefits in various ways. Initially, riparian areas were considered as a type of a wetland. With the advancements in riparian ecology during the last four decades, most scientists consider riparian areas as a unique and different ecosystem than wetlands, although some areas can be considered both as riparian and wetlands.

In general, the properties of riparian zones could bring great benefits. By providing superior agricultural environment and attractive natural landscape, riparian zones could create economic benefits in multiple fields, including agriculture and tourism. Therefore, it is essential to continuously develop an effective and reasonable measure to utilize the land of riparian zones, which could guide us to create more benefits through utilizing it while preventing it from damages and pollution. The riparian area of Three Gorges Reservoir, as a result, is also worth studying through such approach.

After the construction of the Three Gorges dams, the academia in China soon started to pay attention to relevant issues. As one of the related topics, the riparian zone also became one academic interest. Many researchers have done studies on its properties and management. This paper is going to analyze the present studies done in the academia on the utilization of riparian zone in the Three Gorges reservoir, finding both its value and ways to manage and use it. 


\section{Materials and Methods}

Literature Survey Methods: Online database search engines, including CNKI, Web of Science, Google Scholar, Science Direct, Scopus, and Europe PMC were mainly utilized to look up literatures discussing the utilization (or value) of the riparian zone in Three Gorges Reservoir and some publications that evaluate riparian zones in a general way in order to compare and contrast the academic focus of China and that outside of China. "Riparian zone" "evaluation" "utilization" “Three-Gorges Reservoir" "Hydro-fluctuation zone” were keywords being used while searching. For the searching done on CNKI, particularly, keywords in simplified Chinese, including “三峡” “消落 带” “经济” and “利用”, were utilized. In all, 28 pertinent publications were found, of which 5 are about general evaluation of riparian zones.

Literature Analysis and Synthesis: The process of analysis and synthesis of the literatures were done in four steps. The first portion focused on the publication types, which divided the publications into four main groups: journals, proceedings, dissertations, and book chapters. The second part chronicled the publications, analyzing the number of literatures from 2001 to 2020 and showing how the interest in this topic in academia has changed over time. The third section, serving as the most crucial part of analysis and synthesis, categorized the themes of the publications by regarding the how their subjects are related to the utilization of riparian zone.

\section{Results and Discussions}

Publication Types: $80 \%$ of all the publications, except the 5 that are about general evaluation of riparian zones, are journals. On the contrary, other publication types including book chapters, proceedings, and dissertations all had low percentage. Dissertations had a percentage of $12 \%$, whereas proceedings and book chapters respectively had only a percentage of $4 \%$ (Fig. 1). Plus, the majority of the literatures were in English, although the majority of scholars studying on this topic were Chinese researchers. It's also worth noticing that all the dissertations were in Chinese while most of the other types of publications were not.

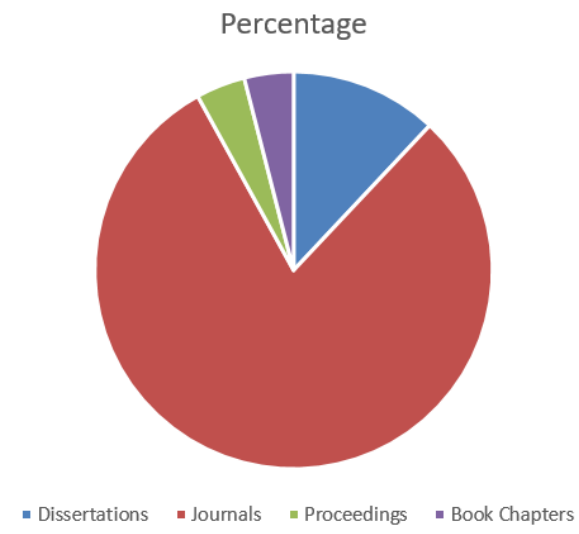

Fig.1: the Percentage of Different Types of Publications Related to the Utilization and Value of the Riparian Zone in Three Gorges Reservoir

Chronicle of publications: First of all, all the 28 publications were published after 2000. (Fig. 2) Only two of the 23 publications were found to be published before 2006, when the Three Gorges Dams completed the construction which serves as a very possible reason. After 2006, the number of publications started to gradually increase and the number never fell back to the level before 2006 again. After that, 2011-2012 also served as a time node when the number of publications started to grow rapidly, probably because the water level of Three Gorges Reservoir reached the highest level in the history in 2012, which therefore raised great attention in the academic field to study on related topics. From 2001 to 2020, approximately 91\% of all the literatures were published after 2006 and 83\% of them were published after 2012. Such trend clearly indicates the increasing of awareness on the importance of riparian zone of Three Gorges Reservoir in China. It is also good to see that such 
trend is still continuing.

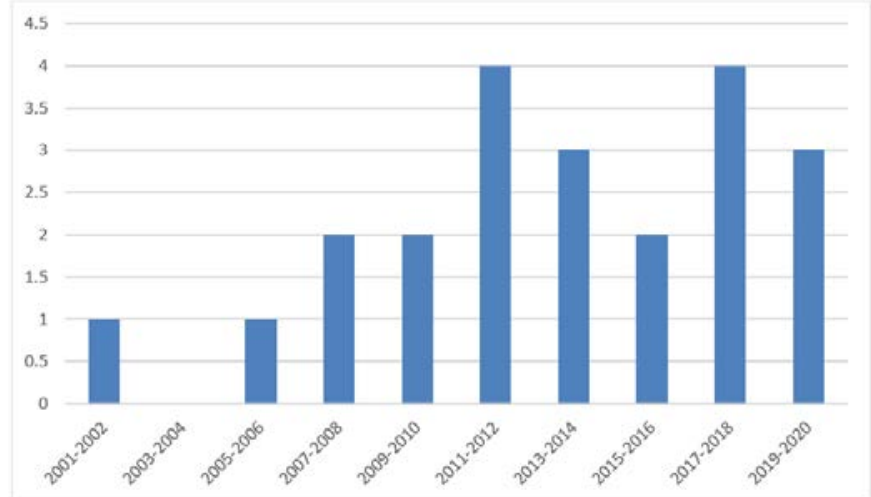

Fig.2: the Number of Publications Published Every Two Years, Related to the Utilization and Value of the Riparian Zone in Three Gorges Reservoir

Thematic Categorization: After all the 25 literatures were reviewed, the subject matters of them were categorized into 3 main groups: ecology and abiotic parameters, tourism, and agriculture, with corresponding subject matters. The percentages of each group of publications are listed in TABLE 1. Although the subject matters present the major focus of the publications, it should not be ignored that many of the literatures covered more than 1 different subject matters. This paper is then going to discuss each of the three categories.

a) Ecology and Abiotic Parameters: This category contains three major subject matters - i) nutrients, ii) environmental conditions, iii) sedimentation and metal, iv) soil, v) temperature, vi) ecosystem, and vii) land use. Although ecology and abiotic parameters could usually be regarded as two distinct categories, many of the publications used in this literature review covered both, and it is hard to determine which one is more important in the literature. Therefore, these two types were combined together. For nutrients, only one of the publications was included, which mainly focus on the distribution and transformation of nutrients in large-scale lakes and reservoirs [6], summarizing management problems and tools to solve them. Environmental technological methods, eco-technological methods, and models are applied in the paper. Nevertheless, the riparian zone is not the most significant theme in this literature. Then, one publication analyzes the content of sedimentation and metal in the riparian zone of Three Gorges Reservoir. [8] Plus, several studies refer to the properties of soil in the riparian zone, which could provide some experience for agricultural utilization. [9, 28] Besides, several literatures mainly analyze the environmental challenges faced by the riparian zone in Three Gorges reservoir, which reveals some limitation while discussing the utilization of the riparian zone, such as temperature and the threat to the ecological safety. [7, 13, 20] As for ecosystem, many publications cover this subject matter. [10, 14, 16, 17, 23, 27] Among these four publications, publication [17] concentrates on evaluating the value of the riparian zone, which divides the ecosystem of the Three Gorges riparian zone into different categories and compares the value of ecosystem service between different modes of utilization. Publication [23] carries out its study in similar measures, which establishes an evaluation system, to measure and predict the effects of four potential protection and utilization modes on the health status of the Three Gorges Reservoir area's riparian zone. Publication [10] and [16], on the other hand, discusses how the use of land would affect the ecosystem. Besides how the ecosystem would be affected by various factors, publication [27] also examines how the ecosystem, influenced by land use, causes huge impacts on water quality in the Three Gorges Reservoir area. Similarly, publication [14] first discusses how the ecosystem is affected by other factors, especially how the ecosystem is damaged, and then studies how it would affect the local riparian zone and vegetation. Finally, two publications take the approach of land use under this category, showing that the land use in Three Gorges reservoir was under improvement of ecological security and economic benefits. [12, 22] 
Table 1: The percentage of each category based on the publications related to the utilization and value of the riparian zone in Three Gorges reservoir. (Some publications covered various subject matters)

\begin{tabular}{|l|l|l|}
\hline Category & Subject Matter & Percentage of Publications (\%) \\
\hline a)Ecology and Abiotic Parameters & $\begin{array}{l}\text { i)Nutrients } \\
\text { ii)Land Use } \\
\text { iii)Sedimentation and Metal } \\
\text { iv)Soil } \\
\text { v)Environmental Challenges } \\
\text { vi)Ecosystem }\end{array}$ & 56 \\
\hline b)Tourism & & 9 \\
\hline c)Agriculture & $\begin{array}{l}\text { i)Agro-ecological } \\
\text { ii)Revegetation } \\
\text { iii)Compensation to Farmers }\end{array}$ & 35 \\
\hline
\end{tabular}

b) Tourism: Only two publications found were found to evaluate the value and utilization of the riparian zone of Three Gorges Reservoir from the perspective of tourism. [15, 25] Publication [15] takes the water-fluctuation zone in Three Gorges Reservoir as an instance, to explain the passive effect of riparian zone to tourism, including impacts on tourist attraction, environment, management, and potential opportunities, which provides valuable ideas on how to utilize the riparian zone rationally from the perspective of tourism. Publication [25], however, focuses on a narrower and more specific subject: the landscape design of riparian zone. This paper also takes the riparian zone in Three Gorges as an example, putting forward a theoretical framework of ecological landscape design of urban coastal strip, which provides a practical and feasible basis for future scientific and rational development and utilization.

c) Agriculture: $35 \%$ of the publications were found to have a subject matter on agriculture. [9, 11 , 18, 19, 21, 24, 26] They were then divided into four groups depending on their subject matters, which are i) agro-ecological, ii) vegetation, iii) compensation to farmers, and iv) general production of local agriculture. Two of the publications took a directly agro-ecological under this theme. [11, 26] One divides the Three Gorges reservoir into four sections based on the fuzzy cluster analysis method of ISOTATA. By analyzing the eco-economic properties of each section, direction and orientation for the development of eco-economy and measures to protect ecological environment are proposed. Therefore, the paper contributes to pave the way for agricultural sustainable development in the Three Gorges reservoir. [11] The other publication, however, concentrates on one paradox faced by the government: whether to use the flooded riparian land along the Three Gorges reservoir or not. The study utilizes various techniques including ESs and Emergy analysis to evaluate the issue, and finally draws the conclusion that appropriate management instead of complete prohibition is necessary. The method of Emergy analysis is also used by publication [21]. The study evaluates the environmental performance of three agricultural production systems--cropping, poultry rearing, and fish raising--in the riparian zone of Three Gorges reservoir, and eventually finds out that a more environmentally-friendly way of production should be advocated in the cropping system and policy supports should be provided for farmers to develop poultry rearing and fish raising systems to increase their income. Besides, this paper also mentions the dilemma discussed by publication [26], and suggests the cooperation between the government and local farmers instead of total prohibition as well. Some other publications focus on more specific subject, such as revegetation. [9, 18, 24] Publication [9], as described in the first category, mainly focuses on how revegetation in the riparian zone would affect soil bacterial diversity. The other two, nonetheless, mainly discuss vegetation reconstruction itself, putting forward its significance not only in ecosystem, but also in economy. Finally, one publication [19] analyzes the farmers' willingness of ecological fallow economic compensation in the Three Gorges reservoir area, which could be regarded as the fundamental study for further cooperation between government and farmers discussed by publication [21] and publication [26].

Future Expectations: Generally speaking, the major space for development remaining in Chinese academia on this topic is that general theory is too insufficient. To compare and contrast, several publications outside China were reviewed, which provided general theocratic analysis and strategies on relevant subject matters. [1, 2, 3, 4, 5] For example, publication [1] discusses the issue on how 
riparian buffers could create economic value. To the contrary, although studies done in Chinese academia cover some aspects of the economic value of riparian zone, not one conclude them as a whole or regard it as an independent subject. Another example is publication [5], which analyzes the landholder's decisions about riparian zone management. Such studies could provide valuable experience for further research. For instance, the results and experience derived from this study could be utilized in study on the cooperation between government and landholders. In particular, studies on the cooperation between local government and farmers in Three Gorges reservoir would benefit a lot if previous studies could provide some analysis on how farmers usually manage the riparian zones in Three Gorges reservoir. Thus it would be a significant goal to achieve in the future Chinese academia, to develop more systematic and theoretical basis.

\section{Conclusion}

In Northern America and most European countries the study of riparian areas has been a focal point in natural resources for decades. Based on such academic circumstances, many systematic studies have been made, including those that focus on the economic evaluation of riparian zones. In contrast, very few scientific publications in China make systematic studies on riparian zones in a general way. Namely, almost all the relevant publications in China focus on only one specific aspect. As a result, a general evaluation on the value of riparian zones is in deficiency as well. Howbeit, as the construction of Three Gorges Dam drew huge attention from the academic field, the academic interest in the riparian zone of Three Gorges Reservoir gradually increased thereafter. Such exponential increase of publications referring to the riparian zones suggests that their importance has been gradually recognized. Based on such optimistic trend, comprehensive understanding of riparian areas, which could help us discover more effective and sustainable management, could serve as a key subject to study on in the academic field in the future. As many studies have discussed the economic value of riparian zones in some certain specific aspects, still a holistic research to integrate those factors is in need. With such theoretical fundament, the riparian zone of Three Gorges Reservoir would be more beneficial to the local. What's more, the public's awareness on the significance of riparian zones, and the utilization of these zones need to improve. It would be difficult to promote the utilization as well as prevent damage and pollution in practice without the public's support.

\section{References}

[1] Qiu, Z., Prato, T., \& Boehrn, G. (2006). Economic Valuation Of Riparian Buffer And Open Space In A Suburban Watershed1. Journal of the American Water Resources Association, vol.42, no.6, pp.1583-1596. doi:10.1111/j.1752-1688.2006.tb06022.x

[2] Münch, A., Nielsen, S. P., Racz, V. J., \& Hjalager, A. (2016).Towards multifunctionality of rural natural environments?-An economic valuation of the extended buffer zones along Danish rivers, streams and lakes. Land Use Policy, vol.50, pp.1-16. doi:10.1016/j.landusepol.2015.08.024

[3] Stutter, M. I., Chardon, W. J., \& Kronvang, B. (2012). Riparian Buffer Strips as a Multifunctional Management Tool in Agricultural Landscapes: Introduction. Journal of Environmental Quality, vol. 41, no, 2, pp. 297-303. doi:10.2134/jeq2011.0439

[4] Yu, J., \& Belcher, K. (2011). An Economic Analysis of Landowners' Willingness to Adopt Wetland and Riparian Conservation Management. Canadian Journal of Agricultural Economics/Revue Canadienne D'agroeconomie, vol.59, no.2, pp.207-222. doi:10.1111/j.1744-7976.2011.01219.x

[5] Fielding, K. S., Terry, D. J., Masser, B. M., Bordia, P., \& Hogg, M. A. (2005). Explaining landholders' decisions about riparian zone management: The role of behavioural, normative, and control beliefs. Journal of Environmental Management, vol.77, no.1, pp.12-21. doi:10.1016/j.jenvman.2005.03.002

[6] Shen, Z. (2013). Distribution and transformation of nutrients and eutrophication in large-scale 
lakes and reservoirs: The Three Gorges Reservoir. Heidelberg: Springer.

[7] Zhang, Q., \& Lou, Z. (2011). The environmental changes and mitigation actions in the Three Gorges Reservoir region, China. Environmental Science \& Policy, vol.14 vol.8, pp.1132-1138. doi:10.1016/j.envsci.2011.07.008

[8] Tang, Q., Bao, Y., He, X., Zhou, H., Cao, Z., Gao, P., Zhang, X. (2014). Sedimentation and associated trace metal enrichment in the riparian zone of the Three Gorges Reservoir, China. Science of The Total Environment, pp.479-480. doi:10.1016/j.scitotenv.2014.01.122

[9] Ren, Q., Li, C., Yang, W., Song, H., Ma, P., Wang, C., Morreale, S. J. (2018). Revegetation of the riparian zone of the Three Gorges Dam Reservoir leads to increased soil bacterial diversity. Environmental Science and Pollution Research, vol.25, no.24, pp.23748-23763. doi:10.1007/s11356-018-2333-3

[10] Yang, F., Wang, Y., \& Chan, Z. (2015). Review of environmental conditions in the water level fluctuation zone: Perspectives on riparian vegetation engineering in the Three Gorges Reservoir. Aquatic Ecosystem Health \& Management, vol.18, no.2, pp. 240-249. doi:10.1080/14634988.2015.1040332

[11] Yang Aimin, Wang Lixian, Wang Yujie, Wang Xilin, Zhou Jinxing (2001). Study onthe agroecological-economic regionalization in the Three gorges reservoir area Acta Ecologica Sinica. ;vol.21, no.4, pp.561-568.

[12] Zhang, J., Su, W., \& Zhang, F. (2011). Regional land ecological security evaluation in the case of Chongqing Three Gorges Reservoir ecological economy area based on the PSR model. Retrieved July 29, 2020, from http://www.zghjkx.com.cn/

[13] Song, Z., Liang, S., Feng, L., He, T., Song, X., \& Zhang, L. (2017). Temperature changes in Three Gorges Reservoir Area and linkage with Three Gorges Project. Journal of Geophysical Research: Atmospheres, vol.122, no.9, pp.4866-4879. doi:10.1002/2016jd025978

[14] New, T., \& Xie, Z. (2008). Impacts of large dams on riparian vegetation: Applying global experience to the case of China's Three Gorges Dam. Biodiversity and Conservation, vol.17, no.13, pp.3149-3163. doi:10.1007/s10531-008-9416-2

[15] Hua, H. , Jie, W. , Qing-Zhong, M. , \& Yue-Fang, D. . (2010). Impacts of riparian zone in reservoir on tourism and their countermeasures--take the three gorges reservoir for example. Bulletin of Soil and Water Conservation. Cheng Hui. Study on the impact of different land use patterns on the ecosystem of the riparian zone in the Three Gorges reservoir area. 2017 (In Chinese)

[16] Lu D.B (2012). Study on the value of ecosystem service function in the Three Gorges reservoir area - A case study of the Three Gorges reservoir area. vol.2012, no.05, pp.123-132. (In Chinese)

[17] Wang Yong, Liu Yifei, Liu Songbai, Huang Hongwen (2005). Vegetation reconstruction in the water--level--fluctuation zone of the three gorges reservoir Chinese Bulletin of Botany. vol.22, no.5, pp.513-522.

[18] Yi Ke, Xiao Yi (2015). Study on the economic compensation intention and influencing factors of farmers' ecological fallow in the Three Gorges reservoir area. vol.2015, no.09, pp.145 (In Chinese)

[19] Yuan, X., Zhang, Y., Liu, H., Xiong, S., Li, B., \& Deng, W. (2013). The littoral zone in the Three Gorges Reservoir, China: Challenges and opportunities. Environmental Science and Pollution Research, vol.20, no.10, 7092-7102. doi:10.1007/s11356-012-1404-0

[20] Cheng, H., Chen, C., Wu, S., Mirza, Z. A., \& Liu, Z. (2017). Emergy evaluation of cropping, poultry rearing, and fish raising systems in the drawdown zone of Three Gorges Reservoir of China. Journal of Cleaner Production, vol.144, pp.559-571. doi:10.1016/j.jclepro.2016.12.053 
[21] Pang Min, Zhou Qigang, Ma Zezhong, Chen Qian, Zhang Xiaoyuan (2020). The coordination of land use and economic development before and after water storage in the Three Gorges reservoir area. vol.2020, no.01.pp.123-127.(In Chinese)

[22] Yuan Hui, Wang Liao, Huang Chuan, Liu Li, Zhan Yanhui (2006). The model of protection and utilization and ecological health evaluation of the Three Gorges reservoir area. vol.2006, no.05, pp.123-140. (In Chinese)

[23] Xiu Hebin, Xie Zongqiang, Nan Hongwei, Bao Yuhai(2007). Vegetation restoration and sericulture ecological and economic development model in Three Gorges reservoir area. vol.2007, no.23, pp.231-135. (In Chinese)

[24] Wang hu (2010). Research on landscape design of drift zone - A case study of Jialing River in Chongqing. (In Chinese)

[25] Chen, C., Cheng, H., Jia, J., Wang, X., \& Zhao, J. (2019). Use it or not: An agro-ecological perspective to flooded riparian land along the Three Gorges Reservoir. Science of The Total Environment, vol.650, pp.1062-1072. doi:10.1016/j.scitotenv.2018.09.062

[26] Zhang, J., Li, S., \& Jiang, C. (2020). Effects of land use on water quality in a River Basin (Daning) of the Three Gorges Reservoir Area, China: Watershed versus riparian zone. Ecological Indicators, 113, 106226. doi:10.1016/j.ecolind.2020.106226

[27] YUHAI BAO, XIUBIN HE, JIE WEI, QIANG TANG \& FENG GUO. Soil erosion under different land uses in the riparian zone of the Three Gorges Reservoir, China. Erosion and Sediment Yields in the Changing Environment (Proceedings of a symposium held at the Institute of Mountain Hazards and Environment, CAS-Chengdu, China, 11-15 October 2012) (IAHS Publ. 356, 2012). 